\title{
Untersuchungen über die Wirkung des elektrischen Stromes auf lebende Zellen. I. Das Verhalten der mitotischen Figur unter der Wirkung des Gleichstromes ${ }^{1)}$
}

\author{
Von \\ Noburô Kamiya \\ Kaiserliche Universität Tokyo \\ (Mit 1 Textfigur)
}

Was die Wirkung des elektrischen Stromes auf die mitotischen Figuren anbelangt, wiesen Pentimalli (1909, 1912), MCClendon (1910), WaKayama,2) BotTa (1932) u.a. darauf hin, daß der Gleichstrom beim Durchgang durch die sich teilende Zelle intrazellular eine anodische Verschiebung der Chromosomen hervorruft; deshalb kamen sie zum Schluß, daß die Bewegung der Chromosomen für ihre Elektrophorese gilt. Die Untersuchungsresultate hierüber waren jedoch nicht immer endgültig, und zwar lehnten HARDY (1913), MEIER (1921), ZEIDLER (1925) u.a. die Verlagerung der Teilungsfigur ab. Diese sich widersprechenden Ergebnisse erhielt man, ausgenommen die in vitro kultivierten Hühnerembryoherzen von BoTTA, meistens bei den Keimwurzeln von verschiedenen Pflanzen wie Hyacinthus, Allium, Pisum, Vicia, usw., wobei die obigen Autoren die Wirkung des Gleichstromes bei den Fixierpräparaten feststellten. Es ist selbstverständlich, daß die Fixierpräparate bei solchen Experimenten nicht immer das reale Verhalten des im lebenden Zustande sich befindlichen Zellinnern zum Ausdruck bringen.

Daher bemühte ich mich in der vorliegenden Arbeit das Verhalten der mitotischen Figur, im lebenden Zustand der Zelle mit besonderer Rücksicht auf ihre Verschiebbarkeit unter der genannten Einwirkung zu verfolgen. Die Untersuchungsresultate sind hier je nach der Intensität des Stromes und der Wirkungszeitdauer in Versuch 1 und 2 zusammengestellt.

\section{Material und Methode}

Als Untersuchungsmaterial wurden junge Staubfadenhaarzellen von Tradescantia reflexa verwendet, welche sich in Knospen in ca. 4$5 \mathrm{~mm}$ Länge befinden.

Um beim Experimente die konstante Konzentration des Mediums beibehalten zu können, fügte ich der Feuchtkammer ein zweckmäßig

1) Contributions from the Divisions of Plant-Morphology and of Geneties, Botanical Institute, Faculty of Science, Tokyo Imperial University, No. 188.

2) Zitiert aus der Monographie von FUJII (1931). 
hergestelltes Kanälchen hinzu, in das das Material mit dem umgebenden Medium eingebettet wird. Ich fertigte mir dieses einfach aus zwei in mäßigem Abstand (5 $\mathrm{mm}$ ) und parallel gelegten Glasstäbchen in einem Durchmesser von ca. 80 " und einem Deckglasstückchen in Breite von ca. $6 \mathrm{~mm}$ an. Der Querschnitt des Kanälchens beträgt danach also ungefähr $0,5 \mathrm{~mm}^{2}$. Dann brachte ich mit beiden öffnungen des Kanälchens ein Bröckchen von 2\% Agar-Agar in Berührung, wobei das Agar die gleiche Lösung wie das, das Kanälchen füllende Medium enthält. Als Medium dienten meistens $0,1 \mathrm{~N} \mathrm{KCl}-$ und $2 \%$ Rohrzuckerlösung. Man führt ein Elektrodenende mittels des Mikromanipulators in beide Agarstückchen hinein, um dadurch den elektrischen Strom möglichst gleichmäßig durch das Kanälchen leiten zu können. Die Stromintensität, welche in den folgenden Versuchen gezeigt wird, entspricht derjenigen, die durch das Medium im Kanälchen leitet, und nicht derjenigen, die wirklich durch die Zelle geht. Als Elektroden dienten die für diesen Zweck geeignet, besonders hergestellten unpolarisierbaren 0,1 N KCl Agar-Elektroden (ca. $1 \mathrm{~mm}$ im inneren Durchmesser am vorderen Teil). Da diese eine große Resistanz (über 50,000 Q) haben, erfordert die Stromquelle eine hohe Spannung; dazu dienten erstens Trockenbatterien, maximale Spannung an den Klemmen $135 \mathrm{~V}$. und zweitens, falls es nötig ist, ein selbst hergestellter kleiner Quecksilber-Gleichrichter, Spannung an den Klemmen ca. $660 \mathrm{~V}$. Die Stromstärke im Kanälchen wurde mit Hilfe der zwei Potentiometer geregelt. Die Beobachtungen wurden mittels LEITZ Öl-Immersion $100 \times$ und ZEISS K $15 \times$ ausgeführt.

\section{Versuch 1: Kurzdauernde Wirkung des starken elektrischen Stromes}

Die zu diesem Versuche angewendete Stromstärke betrug ca. zwischen $0,2-1,0 \mathrm{~mA}$, wobei die Wirkungsdauer auf 0,5-5,0 Sek. begrenzt wurde.

Wird ein starker Strom durch die Zelle in der Teilung parallel ihrer Längenachse entlang geleitet, so bemerkt man, daß die Spindelfigur sich als Ganzes nach der Anodenseite der Zelle verschiebt (Fig. 1). Bemerkenswert ist dabei, daß die einzelnen Chromosomen, solange die Zelle durch den Strom noch unbeschädigt bleibt, ihre Lage im Spindelraum fast gar nicht verändern; ja, es findet fast keine relative Bewegung zwischen den einzelnen Chromosomen und der die Chromosomen umgebenden Spindelsubstanz, d.h. dem Atraktoplasma (FUJII 1931) ${ }^{1)}$ statt. Unter der rechtwinkligen Durchströ-

1) FuJII hat in seiner Monographie vorgeschlagen, die den Spindelraum füllende Substanz, in ihrer physikalisch-chemischen Beschaffenheit vom Zytoplasma unterscheidend, das "Atraktoplasma“ zu nennen. 
mung gegen die Teilungsachse bewegen oder biegen sich die Chromosomen innerhalb des Spindelraums auch kaum und die Spindel als Ganzes fast nicht. Der Raummangel an der Anodenseite der Zelle

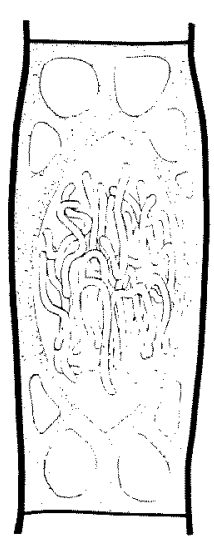

A

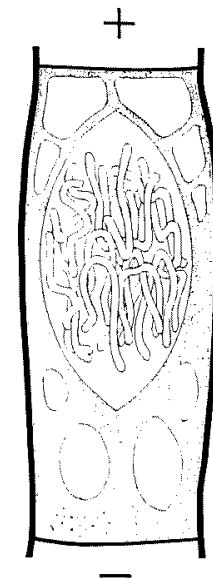

B

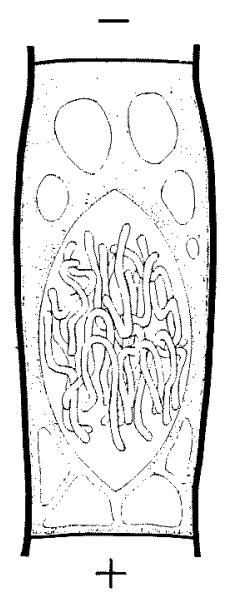

C.

Fig. 1. Eine Haarmittelzelle in der Anaphase, schematisiert. Das angequollene Zytoplasma ist diunn punktiert und das entquollene dicht. A) Vor der Durchströmung. Die Spindel befindet sich in der Mitte der Zelle. B) Durch die Durchströmung bewegt sich die Spindelfigur zur anodischen Seite der Zelle hin. C) Der Pol umgekehrt.

würde hierbei für das Nichtbewegen der Spindelfigur verantwortlich sein.

Falls die Stromintensität verhältnismäßig groß ist, kommt mitunter eine der Plasmolyse ähnliche Erscheinung an der Kathodenseite der Zelle zum Vorschein. Daher geht der Protoplasmawandbelag wahrscheinlich elektroosmotisch?-an der genannten Seite von der Zellwand ab, wobei die Zelle sich im etwas hypotonisch wirkenden Medium befindet. Mit dem Strom-Abschließen wird aber, wenigstens mikroskopisch, eine augenblickliche Wiederherstellung verbunden.

Leitet man den Strom nicht allzu lange durch die Zelle, und wird die Zelle dadurch nicht so beschädigt, so geht die sich einmal anodisch verlagerte Spindelfigur beim Stromunterbruch fast gleichzeitig schnell zu ihrer Anfangsstelle in der Zelle zurück. Bei der in solcher Weise ein- oder vielmal durchströmten Zelle, wobei die Wirkungsbedingungen eine gewisse Grenze nicht überschreiten, konstatierte ich, daß diese eben nach dem Strom-Unterbrechen ihre Mitose weiter fortsetzt und endlich zwei normale Tochterzellen bildet.

Der intrazellulare Hin- und Rückgang der Teilungsfigur tritt bei diesen Versuchen erst in der späten Prophase ein und dauert bis zum Beginn der Scheidewandbildung; dieser ist ja in der Metaund Anaphase am leichtesten.

Beim Übertritt der Stromintensität sowie auch der Wirkungszeitdauer bewegt sich die nach der Anode hin wandernde Spindelfigur infolge der Gelifizierung des Plasmas nicht mehr zurück; das Plasma koaguliert und die Chromosomen werden deutlicher von ihrer 
Umgebung unterscheidbar, als ob sie elektrisch fixiert worden sind. Bei der sich in der späten Anaphase befindlichen Zelle übt solcher starke Strom eine bedeutende Verschiebung der mitotischen Figur aus; sie erhält ihre Form nicht mehr und eine Biegung in ihrer Mitte zeigt, worin der Phragmoplast liegt.

Sehr merkwürdig ist das besonders empfindliche Verhalten des Zytoplasmas in der Mitose bei Durchleitung des elektrischen Stromes. In der Tat wird durch die Stromanwendung eine polarisatorische Quell- und Entquellung des Zytoplasmas hervorgerufen, und zwar findet die Entquellung des Zytoplasmas in der Anodenseite der Zelle und gleichzeitig die Quellung desselben in der Kathodenseite statt. Dieses polarisatorische gegenseitige Verhalten des Zytoplasmas in der einzelnen Zelle beobachtete ich in der sich teilenden, besonders der Endzelle des Haares am deutlichsten, da es dort genügende Mengen von Zytoplasma gibt.

\section{Versuch 2: Langdauernde Wirkung des schwachen elektrischen Stromes}

Ein schwacher Strom $(0,001-0,05 \mathrm{~mA})$ übt in Wirklichkeit morphologisch fast keine sofortige Wirkung auf die Teilungsfigur aus. Jedoch, wenn solcher auf die sich teilende Zelle langdauernd oder immerwährend einwirkt, so tritt eine beträchtliche Hemmung des Teilungsfortganges ein. Wenn eine mitotische Figur in der Prophase mit solchem schwachen Strom fortwährend behandelt wird, so sistiert die Mitose nicht nur ihren weiteren Fortgang, sondern die betroffene Teilungsfigur kehrt zuweilen wieder in den Ruhezustand zurück. Bei der Metakinese sowie auch der Meta- und früheren Anaphase dagegen verzögern sich die Teilungsfortgänge in verschiedenen Graden, sie vollenden jedoch schließlich die Tochterkernbildung.

Der Strom ruft beim Durchgang durch die Zelle keine bedeutende Verschiebung der mitotischen Figur, wie im Versuch 1, hervor, doch entsteht die Scheidewand etwas von der Mitte der Zelle entfernt an einem atypischen Ort. Öfters verschiebt sich die Scheidewandanlage etwas nach der Anode, aber zuweilen etwas nach der Kathode. Aus den Ergebnissen der wiederholten Versuche komme ich zu der Folgerung, daß die Scheidewandbildung unter solcher Bedingung Neigung zeigt, sich nach der Spitze des Haares zu verlagern.

Bei dem Versuch 1 sowie diesem konnte ich jedoch nicht feststellen, ob sich einzelne Chromosomen aus der Spindelfigur loslösen und sich nach der Peripherie der Zelle verschieben, wie die Resultate Pentimalli's und auch die Botta's ergaben. Bisweilen wurden dennoch nach langer Durchströmung selten beträchtliche Ver- 
änderungen in der Anordnung der Chromosomen bemerkt. Diese Veränderungen sind meines Erachtens nicht für eine direkte, sondern vielmehr für eine sekundäre Wirkung des Stromes zu halten; sie treten vermutlich infolge der elektrisch hervorgerufenen Hydratationsveränderung des Zellinnern auf. Nur selten führt die Zelle in der Mitose durch dauernde Anwendung des schwachen Stromes eine frühzeitige Scheidewandbildung herbei; in der Metaphase kommt deshalb schon eine Scheidewandanlage zum Vorschein, welche sich später zu einer solchen unvollendeten entwickelt.

Was das Verhalten des Zytoplasmas bei diesem Versuche betrifft, so erfährt es morphologisch fast keine bedeutende Veränderung, und zwar findet weder die elektrophoretische Verschiebung noch eine auffallende polarisatorische Quell- und Entquellung desselben statt. Wird der Strom immerdauernd schräg gegen die Haarachse geleitet, so findet die Scheidewandbildung auch rechtwinklig gegen dieselbe statt, wobei sie jedoch, wie oben erwähnt wurde, nicht immer in der Zellmitte, sondern manchmal am atypischen Orte liegt.

\section{Schlußbetrachtung}

Aus den Ergebnissen der vorliegenden Versuche (Versuch 1) stellte ich erstens fest, daß unter der Einwirkung des Gleichstromes auf die lebenden Zellen von Tradescantia-Haaren keine relative Bewegung zwischen den Chromosomen und der sie umgebenden Spindelsubstanz (Atraktoplasma) eintritt, indem die Spindel als Ganzes mitsamt ihrem Innern nach der Anode fortgeht; und zweitens, wenn die Spindelfigur beim Stromunterbruch sofort zur Anfangsstelle zurückkehrt, so nimmt sie wieder die Lage der Zellmitte ein.

Bekannt ist, daß die elektrophoretische Verschiebungsfähigkeit des Teilchens nur wenig auf seinem Innern, sondern vielmehr auf der Oberflächen-Eigenschaft, nämlich auf dem Zeta-Potential beruht; danach scheint es mir immerhin noch nicht einwandfrei geklärt zu sein, daß die anodische Bewegung der Chromosomengruppe oder der Spindel der Ladung der Chromosomen zugeschoben werden kann. Falls man den Fortgang der mitotischen Figur für ein elektrophoretisches oder elektroosmotisches Verhalten ansieht, bleibt die durch den Stromunterbruch hervorgerufene Erscheinung des sofortigen Rückganges oder der Herbewegung der Spindelfigur unerklärlich, es sei denn, daß man eine starke Elastizität des Protoplasten annimmt.

Das Verhalten der Spindelfigur beim Versuch 1, in dem keine relative Bewegung der Chromosomen gegen die Spindelsubstanz ein- 
tritt, überzeugt, daß die durch den elektrischen Strom hervorgerufene Quell- und Entquellbarkeit des Zytoplasmas für die intrazellulare Verschiebbarkeit der Spindelfigur eine wichtige Rolle spielt.

Es ist eine bekannte Tatsache, daß der Gleichstrom eine Störungswirkung des Ionenkonzentrationsgleichgewichts auf beiden Seiten des Diaphragmas ausübt, und zwar nimmt die H-Ionenkonzentration auf der Anodenseite ab und auf der Kathodenseite zu (vgl. Bethe, A. u. Toropoff, T. $1915 \mathrm{a}, \mathrm{b}$ ). Dieselbe Beziehung kann auch für die Zelle, die mit der Zell- und Plasmamembran verschlossen ist, gefolgert werden, indem das Zytoplasma an der Anodenseite der Zelle (infolge der H-Ionenkonzentrationszunahme) entquillt; und dagegen an der Kathodenseite stark quillt. Unter solchen Umständen ist es begreiflich, daß die Spindelfigur zwischen den beiden Scheidewänden beim Ein- und Abschalten des Stromes wegen der polarisatorischen Hydratationsveränderung des Zytoplasmas lediglich passiv hin- und hergeschoben wird.

Die weitere Bearbeitung über die Stromwirkung sowie das Ladungsproblem des Zell- und Kerninnern bleibt einem zukünftigen Versuche vorbehalten, da ich dafür vielseitiger und ergänzender Untersuchungen bedarf.

Zum Schluß sei es mir gestattet, Herrn Dr. Sinotô, unter dessen wohlwollender Leitung die vorliegende Arbeit entstanden ist, an dieser Stelle meinen verbindlichsten Dank auszusprechen. Desgleichen bin ich Herrn Dr. WADA für seine liebenswürdigen Anweisungen bei der Durchführung dieser Untersuchungen zu großem Danke verpflichtet.

\section{Zusammenfassung}

Die Verschiebbarkeit der mitotischen Figur unter der Einwirkung des Gleichstromes wurde bei den Staubfadenhaarzellen von Traciescantia reflexa im lebenden Zustande untersucht. Die wichtigen Ergebnisse lauten wie folgt:

1. Die Spindelfigur verlagert sich unter der Einwirkung eines geeignet starken Stromes als Ganzes nach der Anode, wobei eine relative Bewegung zwischen den Chromosomen und der Spindelsubstanz (Atraktoplasma) kaum erkennbar ist; beim Stromunterbruch kehrt sie auch als Ganzes schnell zu ihrer Anfangsstelle zurück und kommt danach wieder in die Mitte der Zelle. Diese reversible Hinund Herbewegung der Spindelfigur wird daher nicht als Elektrophorese der Chromosomen angesehen; sie scheint vielmehr auf verschiedenen polarisatorischen Veränderungen des Zytoplasmas zu beruhen. 
2. Unter dem zu starken Strom oder der zu langen Wirkungsdauer bewegt sich die Spindelfigur einmal auffallend anodisch hin, jedoch infolge der Gelifikation des Zytoplasmas kehrt sie nicht mehr zu ihrer Anfangsstelle zurück.

3. Die Verschiebbarkeit der Spindelfigur fängt bei der späten Prophase an und dauert bis zur Scheidewandbildung, wobei sie in der Meta- und Anaphase am stärksten ist.

Genetik-Abteilung, Botanisches Institut, Naturwissenschaftliche Fakultät der Kaiserlichen Universität zu Tokyo

\section{Literaturverzeichnis}

Bersa, E. u. Weber, F. 1922. Reversible Viskositätserhöhung des Cytoplasmas unter der Einwirkung des elektrischen Stromes. Ber. Deut. Bot. Ges. 40: 254-258.

Bethe, A, u. Toropoff, T. 1915a. Über elektrische Vorgänge an Diaphragmen. Teil I. Die Neutralitätsstörung. Zeit. physikal. Chemie 88:686-742.

- u. - 1915b. U̇ber elek trische Vorgänge an Diaphragmen. Teil II. Die Abhängigkeit der Größe und Richtung der Konzentrationsänderungen und der Wasserbewegung von der H-Ionenkonzentration. Ebenda 89: 597-637.

Botta, B. 1932. Ricerche sulla carica e sul transporto elettrico della figura cromatica delle cellule in mitose in culture di cuore embrionale di pollo (Nota Preventiva). Arch. exp. Zellforsch. 12: 455-464.

Fujii, K. 1931. Zytologie in Vergangenheit und Gegenwart (japanisch). 52 S., Verlag Iwanami. Tokyo.

Hardy, W. B. 1913. Note on differences in electrical potential within the living cell. Jour. Physiol. 47 : 108-111.

McClendon, J. F. 1910. On the dynamics of cell-division. I. The electric charge on colloids in living cells in the root tips of plants. Arch. f. Entw.-Mech. 31: $80-90$.

Meier, H. F. A. 1921. Effect of direct current on cells of root tip of Canada field pea. Bot. Gaz. 72 : 113-138.

Pentimalli, F. 1909. Influenza della corrente elettrica sulla dinamica del processo cariocinetico. Arcb. Entw.-Mech. 28: 260-276.

- 1912. Sulla carica elettrica della sostanza nucleare cromatica. Ebenda $34: 444-451$.

Samejima, R. 1927. U̇ber die durch den elektrischen Strom herbeigeführte Veränderung der Ionen-Konzentration in der Zelle von Tradescantia virginica (japanisch). Act. Medi. Hokkaidon $€$ nsia 5: 43j-470.

Wada, B. 1935. Mikrurgisebe Untersuchungen lebender Zellen in der Teilung. II. Das Verhalten der Spindelfigur und einige inrer physikalischen Eigenschaften in den somatischen Zellen. Cytologia 6: 381-406.

Yamaha, G. 1936. Über die physikalisch-chemischen Untersuchungen der Karyokinese (japanisch). Bot. and Zool. (Tokyo) 4:305-515.

Zeidler, J. 1925. Beiträge zur Frage des Galvanotropismus der Wurzeln. Bot. Archiv 9 : 157-193. 